\title{
Diet and Nutritional Factors Related to Symptomatic Gallstone Disease in Women
}

\section{Mercedes Gonzalez Hita1 ${ }^{1}$, Carolina Batis-Ruvalcaba ${ }^{2}$ and Sergio Sanchez-Enriquez ${ }^{\text {* }}$}

${ }^{1}$ Department of Molecular and Genomic Biology, University Center of Health Sciences, University of Guadalajara, Guadalajara, Jalisco, Mexico ${ }^{2}$ Department of Health Sciences, Universidad del Valle de Atemajac, Campus Guadalajara, Mexico

\begin{abstract}
Background: Gallstone Disease (GD) results from the interaction of genetic predisposition and environmental factors such as physical activity, diet and food habits that are characteristic of each culture. Female gender, aging, obesity and insulin resistance are strongly associated to gallstone formation. Female Mexican population presents high prevalence of obesity and GD. Hence our aim was to establish the relationship between GD, dietary constituents and nutritional factors in women with symptomatic cholelithiasis.
\end{abstract}

Methods: We performed a case-control study in 93 women with symptomatic gallstones and 95 controls. Evaluations included clinical aspects, anthropometry, 24-hours dietary recalls, food habits and physical exercise.

Results: Family history of GD was present in $53 \%$ of GD patients, $54 \%$ showed insulin resistance. GD women, compared to controls, had more overweight and obesity ( $83 \%$ vs. $69 \%)$, higher waist-to-hip ratio $(0.869 \pm 0.06$ vs. $0.838 \pm 0.063, p=.001)$, consumed lesser meals /day $(2.91 \pm 0.76$ vs. $3.61 \pm 0.81 p<0.001)$, ingested more energy (2186 kcal vs. $1366 \mathrm{kcal} p<0.001)$, more total fat $(65 \mathrm{vs} .43 \mathrm{~g} /$ day; $p<0.001)$ and more portions of simple sugars per $1000 \mathrm{kcal}(2.5 \mathrm{vs.} 2.0 \mathrm{p}=0.025)$. Fewer GD women consumed dietary fiber recommended allowance ( 3 vs. $25 \%$ p $<0.0001$ ). Overnight fasting periods were longer in the GD group. Most patients and controls had a sedentary life style.

Conclusion: Obesity, abdominal adiposity, insulin resistance and nutritional factors such as excessive intake of total energy, total fat, simple sugar and long fasting periods; constitute risk factors for gallstone formation. Meanwhile, adequate dietary fiber intake is a protective factor in this population of Mexican women.

Keywords: Cholelithiasis; Food habits, Risk factors; Western Mexico

Abbreviations: FAO: Food and Agriculture Organization of the United Nations; GD: Gallstone Disease; WHO: World Health Organization

\section{Introduction}

Cholesterol stones, the most common form of Gallstone Disease (GD), are a major public health concern in developed countries [13]. The overall prevalence of cholelitiasis in industrialized countries is estimated to be 6-22\% [4]. In Mexican population, cholesterol gallstone formation is a highly frequent condition. The reported prevalence of GD in Mexicans living in the United States is $8.9 \%$ for men and $26.7 \%$ for women [5]. Slightly lower prevalence has been found in subjects living in Mexico City, $14.1 \%$ in general population, $5.8 \%$ and $19.7 \%$ for men and women, respectively [6]. In addition, it has been found in all populations of the world that women are more susceptible than men, to present GD [5].

The etiology of GD is multifactorial. Unmodifiable risk factors include female gender, aging and genetic susceptibility. While modifiable or environmental risk factors include obesity [7-9], weight cycling and periods of rapid weight loss, type 2 diabetes mellitus, hypertriglyceridaemia, cholesterol-lowering drugs (fibrates), smoking and sedentary lifestyle [4,10]. In addition, insulin resistance (IR) [11] and metabolic syndrome have been established as major conditions involved in the pathogenesis of GD [12].

Vast information has been published on the relationship between diet and cholesterol gallstone formation [13-15], although some of this information is contradictory. The most conclusive dietary factors associated with GD are excessive calorie intake, saturated fat and refined sugars as risk factors. Fiber ingestion and moderate alcohol consumption are protective factors [15-17]. In addition, long fasting periods have been found to be associated with gallstone formation.
On the contrary, shorter overnight fasting has been found protective against gallstones, particularly in young women $[4,18]$.

Despite the high prevalence of GD and its economic consequences, there is not enough information about the relationship of diet and gallstones in Mexican population. Knowledge about nutritional and diet related risk factors for GD formation would be useful to design strategies for preventing cholelitiasis in Mexican women. Therefore we conducted the present study with the purpose of establishing the relationship between GD, IR, dietary constituents and nutritional factors among women from Western Mexico.

\section{Materials and Methods}

\section{Assessment of nutritional factors}

Anthropometric parameters were measured, including body weight, height, waist circumference and hip circumference. Body Mass Index (BMI) was calculated as weight in kilograms divided by the squared height in meters $\left(\mathrm{kg} / \mathrm{m}^{2}\right)$. Waist circumference was measured at the midlevel between the lowest rib and the iliac crest with the subject standing and breathing normally. Hip circumference was measured at the widest point between the hip and the buttock [19]. The waist-to-

*Corresponding author: Sergio Sanchez-Enriquez, Sierra Mojada \# 950, Col Independencia, C.P. 44340, Guadalajara, Jal., México, Tel: (52)(33)10585287; E-mail: serlucis@hotmail.com

Received September 25, 2014; Accepted November 21, 2014; Published November 23, 2014

Citation: Gonzalez-Hita M, Batis-Ruvalcaba C, Sanchez-Enriquez S (2014) Diet and Nutritional Factors Related to Symptomatic Gallstone Disease in Women. J Clin Case Rep 4: 458. doi:10.4172/2165-7920.1000458

Copyright: () 2014 Gonzalez-Hita M, et al. This is an open-access article distributed under the terms of the Creative Commons Attribution License, which permits unrestricted use, distribution, and reproduction in any medium, provided the original author and source are credited. 
hip ratio was defined as the waist circumference $(\mathrm{cm})$ divided by the hip circumference $(\mathrm{cm})$. Classification of body mass index was made according to WHO recommendations, as follows: BMI $<25 \mathrm{~kg} / \mathrm{m}^{2}$, normal; $25-29 \mathrm{~kg} / \mathrm{m}^{2}$, overweight and $\geq 30 \mathrm{~kg} / \mathrm{m}^{2}$, obesity.

Lifestyle nutritional factors were assessed by an interview; included questions were weight reduction treatments, number of meals per day, overnight fasting hours. Physical activity and exercise performance (sedentary, moderate, active, and high) were evaluated with the use of questions designed to measure both leisure time and work activities.

\section{Assessment of diet}

Diet was assessed by 24-hour dietary recalls and a food-frequency questionnaire performed by a trained nutritionist. Participants were asked to indicate the frequency of consuming a typical serving size of selected foods during the previous year. Energy intake, total fat, saturated, monounsaturated and polyunsaturated fat, cholesterol, fiber, and calcium intake were estimated using the software Nutripac version 1.5 (@1992-1995); this software is based in the nutritional value of Mexican foods. Simple sugars intake was estimated based on the Mexican exchange list for meal planning [20]. Coffee consumption was assessed by a food frequency questionnaire.

Individuals participating in the GD group were asked to describe their diet and nutritional habits, before the occurrence of gallstone symptoms. This procedure was done because symptomatic gallstones are the main cause of dietary changes and modification of food habits, not for medical indication, but because occurrence of acute gastric pain, nausea and vomiting.

\section{Blood samples and biochemical determinations in GD patients}

Peripheral blood samples were collected from patients after overnight fast (12 hours). Glucose was determined with an enzymatic colorimetric test (Human Biochemica and Diagnostica. Wiesbaden, Germany). Insulin was determined using the kit IMX system of ABBOTT (Insulin 2A10, 46-3898/R6) using the micro particle enzyme immune assay (ABBOTT laboratories, North Chicago, IL). Insulin resistance was calculated by means of the homeostasis model assessment (HOMA-IR). HOMA-IR=[fasting insulin $(\mu \mathrm{U} / \mathrm{mL}) \times$ fasting glucose $(\mathrm{mmol} / \mathrm{L})] / 22.5[20,21]$. Insulin resistance was determined as a HOMA value $>2.5$ [22].

\section{Statistical analysis}

We examined the relation between symptomatic GD, dietary and nutritional factors, with Chi-square test $\left(\mathrm{x}^{2}\right)$ and odds ratio (OR) with 95\% confidence interval (CI) for categorical variables such as BMI classification, dieting, physical exercise and coffee consumption. The quantitative variables including diet components, waist circumference, number of meals per day, and hours of overnight fasting were compared with the Student's t test or Mann-Whitney U-test, when necessary. A logistic regression analysis was performed. Significance was established at $\mathrm{P}<0.05$.

\section{Ethical aspects}

Ethics Committee of the hospital approved the study. Each participant signed a written informed consent and the study protocol conformed to the ethical guidelines according to the 1975 Declaration of Helsinki.

\section{Results}

Demographic data for GD women and controls are shown in Table 1. Mean age in GD group was 40.6 years (range from 19 to 69 years), $74 \%$ of these patients were younger than 50 years old. No significant differences in age were observed between the two groups. A family history of cholelithiasic disease was present in 53\% of the GD patients $(\mathrm{p}<0.05)$. Most women with GD, in the present study, were overweight $(48 \%)$ or obese $(35 \%)$. The frequency of overweight $(38 \%)$ and obesity (30\%) in the control group was elevated, but significantly lower than in the group of cases $(p=0.02)$. Twenty five percent of the GD obese patients presented a personal history of overweight or obesity since childhood or adolescence, $35 \%$ gained excessive weight after pregnancy and $40 \%$ become obese in adulthood. An important fact related to obesity is regional body fat distribution. Since GD has been associated with abdominal adiposity, we assessed fat distribution by the ratio waist-to-hip circumference. We found that patients with GD had a significant higher waist-to-hip ratio than control subjects $(\mathrm{p}=0.001)$ (Table 1). Insulin resistance is a condition linked to viscera adiposity, in the present study $53 \%$ of GD women showed IR (HOMA value $>2.5$ ). Twenty seven percent of GD women referred intentional weight reduction treatments, this percentage was similar in the control group and this variable did not represent a risk factor for $\mathrm{GD}(\mathrm{OR}=1.22$; $\mathrm{IC}=0.63-2.36$ ). Similarly, there were no significant differences found in the number of times that patients and control subjects lost weight, and the body weight (kilograms) that they lost per time (Table 1). With regard to dietary habits, we found that the GD women had the habit of having less number of meals per day than controls, $22 \%$ of cases had less than 3 meals per day against $5 \%$ of control subjects $(\mathrm{p}<0.0001)$. Overnight fasting periods tended to be longer in the GD group when compared to controls without reaching statistical significance (13.85 vs. 13.03 hours, $\mathrm{p}=0.059$ ).

At the time of the study, the main occupation of the participants was housewife (55\%), $45 \%$ were involved in a job outside their house, from which only $9 \%$ were professionals. Most individuals have a sedentary lifestyle whose activities were household chores (cooking and cleaning), ( $6 \pm 2 \mathrm{hrs})$, watching television ( $9 \pm 3 \mathrm{hrs}$ ) and sleeping $(9 \pm 1 \mathrm{hrs})$. No significant differences were found in the frequencies of individuals that performed physical exercise. Only $28 \%$ of the

\begin{tabular}{|l|c|c|c|}
\hline & $\begin{array}{c}\text { Patients with gallstones } \\
(\mathbf{n = 9 3 )}\end{array}$ & $\begin{array}{c}\text { Control subjects } \\
(\mathbf{n = 9 5 )}\end{array}$ & $\begin{array}{c}\mathbf{p} \\
\text { value }\end{array}$ \\
\hline $\begin{array}{l}\text { Age (years) } \\
\text { Body mass index } \\
\text { classification, } \mathrm{n}(\%)\end{array}$ & $40.05 \pm 13.36^{*}$ & $43.45 \pm 12.9$ & $\mathrm{NS}+$ \\
\hline \multicolumn{1}{|c|}{ Obesity } & $45(48)$ & $29(30)$ & $0.02++$ \\
\hline Age (years) & $44 \pm 13$ & $45 \pm 11$ & \\
\hline \multicolumn{1}{|c|}{ Overweight } & $32(35)$ & $36(38)$ & \\
\hline Age (years) & $37 \pm 11$ & $35 \pm 10$ & \\
\hline \multicolumn{1}{|c|}{ Normal } & $16(17)$ & $30(32)$ & \\
\hline Age (years) & $33 \pm 13$ & $32 \pm 8$ & \\
\hline Waist-to-hip ratio & $0.869 \pm 0.06^{*}$ & $0.838 \pm 0.063$ & $0.001+$ \\
\hline Waist circumference (cm) & $89.39 \pm 11.28^{*}$ & $86.25 \pm 11.09$ & $\mathrm{NS}+$ \\
\hline Weight reduction, $n$ (\%) & $25(27)$ & $22(23)$ & $\mathrm{NS}++$ \\
\hline Meals pear day, (number) & $2.91 \pm 0.76^{*}$ & $3.61 \pm 0.81$ & $<0.001+$ \\
\hline Overnight fasting, (hours) & $13.85 \pm 3.1^{*}$ & $13.03 \pm 1.64$ & $\mathrm{NS}+$ \\
\hline Exercise, $\mathrm{n}$ (\%) & $26(28)$ & $32(34)$ & $\mathrm{NS}++$ \\
\hline
\end{tabular}

${ }^{*}$ Results are shown in mean \pm standard deviation; +Student's t test; ++ Chi squared test; NS= non significant.

Table 1: Nutritional factors in patients with gallstones and control subjects. 
GD patients and $34 \%$ of the control subjects practice some form of moderate exercise (Table 1).

Main nutrient intakes by patients with gallstones and control subjects are shown in Table 2. There was asignificant difference of $800 \mathrm{kcal}$ in total energy intake ( $2186 \mathrm{kcal}$; cases vs. $1366 \mathrm{kcal}$; controls; $\mathrm{p}<0.001)$. Furthermore, ingestion of protein, cholesterol, fiber, calcium and simple sugars were also significantly higher in GD patients as compare with control subjects. The consumption of total fat in the group of cases was elevated as compared to controls ( 65 vs. $43 \mathrm{~g} /$ day; $\mathrm{p}<0.001$ ). However, the proportions of saturated, monounsaturated and polyunsaturated fat were similar between groups. Fat was derived mainly from animal food sources such as whole milk, eggs and pork meat; which contain mainly saturated fat and high amount of cholesterol. Neither coffee consumption habit, nor the quantity of coffee consumed (cups per day) was significantly different among cases and controls. Energy-adjusted nutrient intakes (adjusted per each 1,000 kcal consumed /day) are summarized in Table 3. Most dietary components (nutrient densities) were not different between groups, with the exception of protein and simple sugars. Control subjects consumed in proportion, more protein $(\mathrm{p}=0.022)$ and less simple sugars $(\mathrm{p}=0.025)$ than cases. The average intake of fiber was similar in both groups of subjects $(\mathrm{p}=0.065)$, but comparing the groups according to fiber recommendation achievement of $\geq 14 \mathrm{~g} / 1000 \mathrm{kcal}$ per day, more controls accomplished this amount of ingested fiber $(25 \%)$ than cases $(3 \%),(\mathrm{OR}=0.99, \mathrm{IC}=0.29-0.341$; $\mathrm{p}<0.0001)$.

Table 4 displays the results of final multiple logistic regression model. Number of meals per day had an inverse association with symptomatic gallstones, whereas waist-to-hip ratio and total energy intake were directly related to the risk of GD.

\section{Discussion}

Obesity is a complex pathological condition related to the interaction among genetic and environmental risk factors such as high calorie diets, fast food, and sedentary lifestyle; most of these factors are due to economic growth, urbanization, and lack of nutritional

\begin{tabular}{|c|c|c|c|}
\hline Nutrient & $\begin{array}{c}\text { Patients with } \\
\text { gallstones }(n=93)\end{array}$ & $\begin{array}{l}\text { Control subjects } \\
(n=95)\end{array}$ & $\mathbf{p}$ \\
\hline Total energy intake (kcal) & $2186(1768-2788)^{*}$ & $1366(1088-1668)$ & $<0.001+$ \\
\hline Carbohydrates (g) & $318.4(244.2-390.1)^{*}$ & $201.2(141.5-251.2)$ & $<0.001+$ \\
\hline Protein $(\mathrm{g})$ & $87.3(65.4-107.9)^{\star}$ & $49.3(39.0-62.0)$ & $<0.001+$ \\
\hline Fat $(\mathrm{g})$ & $65.6(46.1-94.6)^{*}$ & $43.4(29.6-54.2)$ & $<0.001+$ \\
\hline Saturated fat (\% of total kcal) & $10.1(7.7-13.8)^{\star}$ & $11.17(8.0-13.7)$ & NS++ \\
\hline Monounsaturated fat (\%of total kcal) & $9.6(8.0-12.2)^{\star}$ & $9.8(7.1-13.3)$ & NS++ \\
\hline Polyunsaturated fat (\% of total kcal) & $6.6(4.1-9.1)^{\star}$ & $9.8(7.1-13.3$ & NS++ \\
\hline Cholesterol (mg) & $211(135-571)^{\star}$ & $6.1(3.6-8.7)$ & $<0.001+$ \\
\hline Fiber $(\mathrm{g})$ & $19.6(14.2-25.8)^{*}$ & $12.3(8.3-18.2)$ & $<0.001+$ \\
\hline Calcium (mg) & $999(697-1502)^{*}$ & $599(391-773)$ & $<0.001+$ \\
\hline Simple sugars (portion) & $6(3-10)^{*}$ & $599(391-773)$ & $<0.001+$ \\
\hline Coffee $(\%)$ & $44(47.8) \&$ & $3(1-5)$ & NS++ \\
\hline Coffee (cups) & $1(1-2) \&$ & $\begin{array}{c}34(35.8) \\
1(0.88-1.63)\end{array}$ & NS+ \\
\hline
\end{tabular}

Results are shown in mean (minimal-maximal values); \& results are shown in mean (\%); +Student's

t test; ++ Chi squared test

Table 2: Daily intake of nutrients in patients with gallstones and control subjects.

\begin{tabular}{|l|c|c|}
\hline Nutrient & $\begin{array}{c}\text { Patients with } \\
\text { gallstones }(\mathbf{n = 9 3 )}\end{array}$ & $\begin{array}{c}\text { Control subjects } \\
(\mathbf{n}=95)\end{array}$ \\
\hline Carbohydrates $(\mathrm{g} / 1000 \mathrm{kcal})$ & $142.7(127-156)^{*}$ & $146.4(128-167)$ \\
\hline Protein $(\mathrm{g} / 1000 \mathrm{kcal})$ & $36.9(32.7-42.3)^{*}$ & $36.0(31.9-41.2$ \\
\hline Fat $(\mathrm{g} / 1000 \mathrm{kcal})$ & $30.9(24.4-38.4)^{*}$ & $31.3(23.9-39.2)$ \\
\hline Cholesterol $(\mathrm{mg} / 1000 \mathrm{kcal})$ & $93.1(61.7-219.8)^{*}$ & $89.9(60.0-204.0)$ \\
\hline Fiber $(\mathrm{g} / 1000 \mathrm{kcal})$ & $9.1(7.0-11.5)^{*}$ & $9.8(7.0-14.2)$ \\
\hline Fiber $\geq 14 \mathrm{~g} / 1000 \mathrm{kcal}, \mathrm{n}(\%)$ & $3(3 \%)+$ & $24(25 \%)$ \\
\hline Calcium $(\mathrm{mg} / 1000 \mathrm{kcal})$ & $440.0(318.6-577.9)^{*}$ & $\mathrm{NS}$ \\
\hline Simple sugars (portion/1000 kcal) & $2.5(1.3-4.1)^{*}$ & $423.4(307.3-587.8)$ \\
\hline
\end{tabular}

Note: Dietary nutrient densities expressed per 1,000 kcal. *Results are shown in mean (minimal- maximal values), t student test; + Chi squared test. Table 3: Daily dietary nutrient densities in patients with gallstones and control.

\begin{tabular}{|l|c|c|c|}
\hline Variable & Coefficient $(\boldsymbol{\beta}$ & $\mathbf{P}$ (Wald test) & Odds ratio \\
\hline Meals pear day, (number) & -2.36 & 0 & $\mathbf{9 5 \%}$ Cl for odds ratio \\
\hline Waist-to-hip ratio $((\mathrm{cm} / \mathrm{cm}) * 10)$ & 0.905 & 0.012 & 0.094 \\
\hline Total energy intake $(100 \mathrm{kcal})$ & 0.289 & 0 & 2.47 \\
\hline
\end{tabular}

Forward method, independent variables included in the model: age, Meals per day (number), Body mass index (kg/m2), Waist-to-hip ratio ((cm/cm) $\left.{ }^{\star} 10\right)$, Total energy intake (100 kcal), Protein (g/1000 kcal), fiber (g/1000 kcal), Simple sugars (portion/1000 kcal). Hosmer and Lemshow test $p=0.47$

Table 4: Final multiple logistic regression model for symptomatic gallstones $(R 20.673, p=0.000$. 
education [23]. These risk factors were documented in the present study in the GD women; since they belong to the middle class, live in a big city (Guadalajara) and they don't consume a correct diet. Childhood obesity predisposes to several metabolic, physiological and clinical complications that lead to several chronic diseases in adulthood, in addition to GD [24,25]. In the present study we have found that $25 \%$ of our cases presented excess body weight since childhood or adolescence, and $35 \%$ developed obesity after pregnancy. There is a linear correlation among BMI and markers of inflammation [26,27], dyslipidemia, oxidative stress, endothelial damage, as well as dysfunction and morphological vascular changes, increasing the risk of coronary heart disease in early adulthood [28-30]. We consider that GD patients in our study, due to the presence of genetic predisposition, environmental risk factors, as well as to the high frequency of overweight and obesity, are a latent risk group to develop subsequent metabolic alterations associated to the insulin resistance syndrome that eventually leads to type 2 diabetes and cardiovascular diseases. Since most alterations related to obesity begin at early stages of life [31], attempts to prevent and diagnose pathological conditions should also start early identifying obese young adults and children at increased risk of chronic diseases.

Obese individuals are more likely than normal weight subjects to acquire GD $[16,17]$. In this case-control study, our results indicate that obesity is more frequent among women with gallstones than controls; these findings are in accordance with those reported in other populations [32-34]. It has been suggested that obesity raises the risk of cholesterol gallstones by increasing biliary secretion of cholesterol and disturbing vesicular motility [35]. A high waist-to-hip ratio, which reflects abdominal distribution of body fat, has been associated with gallstones mostly in men [36,37]. Nevertheless, in the present study we found that a higher waist-to-hip ratio in women was also correlated with GD. Abdominal adiposity is associated to insulin resistance and the metabolic syndrome; both conditions have been found to be related to gallstone formation $[38,39]$. High fasting insulin levels have been reported to increase the risk of GD among women [40]. The metabolic syndrome was reported to be strongly associated to GD in Mexican adults [12]. In the present study, 58\% of the GD women showed insulin resistance, these patients are likely to present other metabolic alterations, such as impaired glucose tolerance, dyslipidemia (high plasma triglycerides and low HDL-C), and hypertension. Weight cycling and rapid body weight losses in obese patients are factors associated with gallstones formation [41]. It has been reported that some obese patients following a weight loss treatment develop asymptomatic gallstones. Our study of symptomatic GD women showed that most cases maintained stable and elevated weight for many years before the appearance of symptomatic cholelithiasis. In addition, some of the GD women have been overweight since adolescence and few cases have had episodes of weight fluctuations. Furthermore, we did not included severely obese women with weight cycling patterns. Our data did not show significant differences in history of weight reductions between cases and controls. This could be explained considering that the study sample belongs to a low-income social class; in which weight reduction is not so usual and therefore it may not represent a risk factor for gallstone formation. It has been found that short periods of night fasting protect against gallstones both in men and women [4]. Our results support this finding and clearly indicate that eating fewer times a day was a risk factor for GD in women.

A sedentary lifestyle and an inadequate diet are both significant risk factors for gallstone formation. In general, increased physical activity is associated with a significant reduction in the risk of cholecystectomy in humans [42,43] and in animals [44]. In the present study, we found that physical inactivity was a widespread condition, and that exercise performance was very low and similar in cases and controls. However, potential mechanisms for the antilithogenic effects of exercise beyond lowering body weight have not been clearly described. Previous studies have examined the role of diet as a potential risk factor for cholelithiasis. The principal dietary constituents found in the literature are total energy intake and ingestion of refined sugars, which are directly related to the risk of gallstone formation $[7,16,17]$. Whereas, fiber ingestion [45] and alcohol consumption $[7,8]$ are consistently found to be inversely related to GD. Our findings agreed with reported evidence that increased consumption of simple carbohydrates and excessive energy intake are both risk factors. On the other hand, an adequate fiber ingestion that achieves the recommended dietary allowance was a protective factor for gallstone formation in our study. It is known that estimation of caloric intake is difficult to assess [16]. However, we found a significant difference in energy ingestion between the groups, so that we can clearly conclude that, despite possible measurement errors, energy intake was positively related with GD in this group of women.

Ingestion of refined foods, mainly simple sugars is one of the major contributors to nutritional imbalance [17]. Indeed, most international regulatory agencies committees such as WHO and FAO suggest the use of complex carbohydrates [46]. The Mexican diet has a high content of sweet beverages and soft drinks that are the main sources of simple sugars [47]. In addition to quantity, the quality of carbohydrates is a primary determinant of the digestion speed, absorption and the resulting glycaemia and insulin response [48]. In our study, more than half of GD patients showed a condition of insulin resistance. Hepatic Insulin resistance has been reported as a critical factor to modify liver cholesterol metabolism and biliary cholesterol secretion in animals and humans leading to super-saturated bile and gallstones formation [39]. With regard to fiber ingestion and gallstones formation, our study shows that low fiber intake is associated with an increase in the risk of gallstone development; these results are in accordance with those from the literature [45]. The effects of low fiber ingestion are explained based on the resultant increase in secondary bile acid secretion due to a decrease in colonic motility and a decrease in cholesterol and bile salts fecal excretion [49]. Regarding the effects of total fat intake on GD, a number of studies have reported controversial results $[7,14,17,51]$. In our study, average intake of total fat among GD women was significantly higher than in controls, in agreement with studies showing a positive association between total fat intake and GD $[8,14]$. In the present study, GD women enjoyed traditional Mexican food prepared with pork meat and pork fat contributing to high intake of saturated fat and cholesterol. Also, individuals in our study consumed processed food containing partially hydrogenated fat which contributes to elevated ingestion of Trans fatty acids, which have been reported to increase the risk of GD in men [50,51]. On the contrary, GD women in the present study rarely consumed fish, a good source of $\mathrm{n}$-3-polyunsaturated fatty acids, which have been proposed as a protective factor. The mechanism reported is associated with improvement of bile composition by maintaining cholesterol nucleation time and cholesterol saturation index [52]. Protein intake among the group with gallstones in the present study was slightly higher when adjusted per $1000 \mathrm{kcal}$. This is peculiar since other authors have not found protein intake as a risk factor for GD. However, there are few studies about this relationship and the results are still controversial [53].

Few studies have evaluated the association between coffee intake and GD [54,55]. Our results showed that coffee intake did not seem to be associated to GD. The etiology of cholesterol GD is multifactorial with complex interactions of the environment and the effect of multiple genes 
[56]. There are several polymorphisms found to be associated with the genetic susceptibility to cholesterol gallstone formation in humans with gallstones [57,58]. In the present study we found a high frequency $(53 \%)$ of GD women who referred a family history of cholelithiasic disease, future studies should address the genetic polymorphism associated to GD in Mexican population. Our study provides information about the association between anthropometric parameters, dietary components and food habits in a population of Mexican women who exhibit GD at middle age and may continue to be at high risk for other obesity-related chronic diseases. Therefore, unless some preventive actions are taken in order to modify the adverse nutritional factors, as well as to increase physical activity to diminish the weight gain characteristic of ageing and control the insulin resistance, these patients present a major risk for developing type 2 diabetes and cardiovascular diseases, both leading causes of death in Mexican population.

\section{References}

1. Diehl AK (1991) Epidemiology and natural history of gallstone disease. Gastroenterol Clin North Am 20: 1-19.

2. Jensen KH, Jørgensen T (1991) Incidence of gallstones in a Danish population. Gastroenterology 100: 790-794.

3. Lowenfels AB, Velema JP (1992) Estimating gallstone incidence from prevalence data. Scand J Gastroenterol 27: 984-986.

4. Acalovschi M (2001) Cholesterol gallstones: from epidemiology to prevention. Postgrad Med J 77: 221-229.

5. Everhart JE, Khare M, Hill M, Maurer KR (1999) Prevalence and ethnic differences in gallbladder disease in the United States. Gastroenterology 117: 632-639.

6. Gonzalez Villalpando C, Rivera Martinez D, Arredondo Perez B, Martinez Diaz S, Gonzalez Villalpando ME, et al. (1997) High prevalence of cholelithiasis in a low income Mexican population: an ultrasonographic survey. Arch Med Res 28: $543-547$

7. Maclure KM, Hayes KC, Colditz GA, Stampfer MJ, Speizer FE, et al. (1989) Weight, diet, and the risk of symptomatic gallstones in middle-aged women. N Engl J Med 321: 563-569.

8. Jorgensen T, Jørgensen LM (1989) Gallstones and diet in a Danish population Scand J Gastroenterol 24: 821-826.

9. Misciagna G, Centonze S, Leoci C, Guerra V, Cisternino AM, et al. (1999) Diet physical activity, and gallstones--a population-based, case-control study in southern Italy. Am J Clin Nutr 69: 120-126.

10. Mendez-Sánchez N, Vega H, Uribe M, Guevara L, Ramos MH, et al. (1998) Risk factors for gallstone disease in Mexicans are similar to those found in Mexican-Americans. Dig Dis Sci 43: 935-939.

11. DiehI AK (2000) Cholelithiasis and the insulin resistance syndrome. Hepatology 31: $528-530$.

12. Méndez-Sánchez N, Chavez-Tapia NC, Motola-Kuba D, Sanchez-Lara K, Ponciano-Rodríguez G, et al. (2005) Metabolic syndrome as a risk factor for gallstone disease. World J Gastroenterol 11: 1653-1657.

13. Diehl AK, Haffner SM, Knapp JA, Hazuda HP, Stern MP (1989) Dietary intake and the prevalence of gallbladder disease in Mexican Americans. Gastroenterology 97: 1527-1533.

14. Ortega RM, Fernández-Azuela $M$, Encinas-Sotillos $A$, Andrés $P$, López-Sobale AM (1997) Differences in diet and food habits between patients with gallstones and controls. J Am Coll Nutr 16: 88-95.

15. Méndez-Sánchez N, Zamora-Valdés D, Chávez-Tapia NC, Uribe M (2007) Role of diet in cholesterol gallstone formation. Clin Chim Acta 376: 1-8.

16. Tseng M, Everhart JE, Sandler RS (1999) Dietary intake and gallbladder disease: a review. Public Health Nutr 2: 161-172.

17. Cuevas A, Miquel JF, Reyes MS, Zanlungo S, Nervi F (2004) Diet as a risk factor for cholesterol gallstone disease. J Am Coll Nutr 23: 187-196.

18. Duane WC, Ginsberg RL, Bennion LJ (1976) Effects of fasting on bile acid metabolism and biliary lipid composition in man. J Lipid Res 17: 211-219.
19. [No authors listed] (1995) Physical status: the use and interpretation of anthropometry. Report of a WHO Expert Committee. World Health Organ Tech Rep Ser 854: 1-452.

20. Perez-Lizaur AB, Marvan-Laborde L.SistemaMexicanode AlimentosEquivalentes $1^{\circ}$ edición. Ed. Fomento de Nutrición y Salud, A.C. 2000.

21. Tuan CY, Abbasi F, Lamendola C, McLaughlin T, Reaven G (2003) Usefulness of plasma glucose and insulin concentrations in identifying patients with insulin resistance. Am J Cardiol 92: 606-610.

22. Ford ES, Giles WH, Dietz WH (2002) Prevalence of the metabolic syndrome among US adults: findings from the third National Health and Nutrition Examination Survey. JAMA 287: 356-359.

23. Gonzalez C, Stern MP, Gonzalez E, Rivera D, Simon J, et al. (1999) The Mexico City Diabetes Study: a population-based approach to the study of genetic and environmental interactions in the pathogenesis of obesity and diabetes. Nutr Rev 57: S71-76.

24. Tirosh A, Shai I, Afek A, Dubnov-Raz G, Ayalon N, et al. (2011) Adolescent BM trajectory and risk of diabetes versus coronary disease. N Engl J Med 364 1315-1325.

25. Franks PW, Hanson RL, Knowler WC, Sievers ML, Bennett PH, et al. (2010) Childhood obesity, other cardiovascular risk factors, and premature death. N Engl J Med 362: 485-493.

26. Herder C, Schneitler S, Rathmann W, Haastert B, Schneitler H, et al. (2007) Low-grade inflammation, obesity, and insulin resistance in adolescents. $\mathrm{J}$ Clin Endocrinol Metab 92: 4569-4574.

27. Han TS, Sattar N, Williams K, Gonzalez-Villalpando C, Lean ME, et al. (2002) Prospective study of C-reactive protein in relation to the development of diabetes and metabolic syndrome in the Mexico City Diabetes Study. Diabetes Care 25: 2016-2021.

28. Ciccone MM, Miniello V, Marchioli R, Scicchitano P, Cortese F, et al. (2011) Morphological and functional vascular changes induced by childhood obesity. Eur J Cardiovasc Prev Rehabil 18: 831-835.

29. Beauloye V, Zech F, Tran HT, Clapuyt P, Maes M, et al. (2007) Determinants of early atherosclerosis in obese children and adolescents. J Clin Endocrino Metab 92: 3025-3032.

30. Owen CG, Whincup PH, Orfei L, Chou QA, Rudnicka AR, et al. (2009) Is body mass index before middle age related to coronary heart disease risk in later life? Evidence from observational studies. Int J Obes (Lond) 33: 866-877.

31. Park MH, Falconer C, Viner RM, Kinra S (2012) The impact of childhood obesity on morbidity and mortality in adulthood: a systematic review. Obes Rev 13: $985-1000$.

32. Attili AF, Capocaccia R, Carulli N, Festi D, Roda E, et al. (1997) Factors associated with gallstone disease in the MICOL experience. Multicenter Italian Study on Epidemiology of Cholelithiasis. Hepatology 26: 809-818.

33. Friedman GD, Kannel WB, Dawber TR (1966) The epidemiology of gallbladde disease: observations in the Framingham Study. J Chronic Dis 19: 273-292.

34. Johnston DE, Kaplan MM (1993) Pathogenesis and treatment of gallstones. N Engl J Med 328: 412-421.

35. Méndez-Sánchez N, Chávez-Tapia NC, Uribe M (2004) [Gallbladder disease and obesity]. Gac Med Mex 140 Suppl 2: S59-66.

36. Tsai CJ, Leitzmann MF, Willett WC, Giovannucci EL (2004) Prospective study of abdominal adiposity and gallstone disease in US men. Am J Clin Nutr 80: $38-44$

37. Heaton KW, Braddon FE, Emmett PM, Mountford RA, Hughes AP et al. (1991) Why do men get gallstones? Roles of abdominal fat and hyperinsulinemia. Eur J Gastroentrol Hepatol 3: 745-751.

38. Ruhl CE, Everhart JE (2000) Association of diabetes, serum insulin, and C-peptide with gallbladder disease. Hepatology 31: 299-303.

39. Biddinger SB, Haas JT, Yu BB, Bezy O, Jing E, et al. (2008) Hepatic insulin resistance directly promotes formation of cholesterol gallstones. Nat Med 14 : 778-782.

40. Nervi F, Miquel JF, Alvarez M, Ferreccio C, García-Zattera MJ, et al. (2006) Gallbladder disease is associated with insulin resistance in a high risk Hispanic population. J Hepatol 45: 299-305. 
Citation: Gonzalez-Hita M, Batis-Ruvalcaba C, Sanchez-Enriquez S (2014) Diet and Nutritional Factors Related to Symptomatic Gallstone Disease in Women. J Clin Case Rep 4: 458. doi:10.4172/2165-7920.1000458

41. Syngal S, Coakley EH, Willett WC, Byers T, Williamson DF, et al. (1999) Longterm weight patterns and risk for cholecystectomy in women. Ann Intern Med 130: $471-477$.

42. Utter AC, Whitcomb DC, Nieman DC, Butterworth DE, Vermillion SS (2000) Effects of exercise training on gallbladder function in an obese female population. Med Sci Sports Exerc 32: 41-45.

43. Chuang CZ, Martin LF, LeGardeur BY, Lopez A (2001) Physical activity, biliary lipids, and gallstones in obese subjects. Am J Gastroenterol 96: 1860-1865.

44. Wilund KR, Feeney LA, Tomayko EJ, Chung HR, Kim K (2008) Endurance exercise training reduces gallstone development in mice. J Appl Physiol (1985) 104: 761-765.

45. Morán S, Uribe M, Prado ME, de la Mora G, Muñoz RM, et al. (1997) [Effects of fiber administration in the prevention of gallstones in obese patients on a reducing diet. A clinical trial]. Rev Gastroenterol Mex 62: 266-272.

46. Delzenne NM, Cani PD (2005) A place for dietary fibre in the management of the metabolic syndrome. Curr Opin Clin Nutr Metab Care 8: 636-640.

47. Rivera JA, Barquera S, Campirano F, Campos I, Safdie M, et al. (2002) Epidemiological and nutritional transition in Mexico: rapid increase of noncommunicable chronic diseases and obesity. Public Health Nutr 5: 113-122.

48. Heaton KW, Emmett PM, Symes CL, Braddon FE (1993) An explanation for gallstones in normal-weight women: slow intestinal transit. Lancet 341: 8-10.

49. Marcus SN, Heaton KW (1986) Intestinal transit, deoxycholic acid and the cholesterol saturation of bile--three inter-related factors. Gut 27: 550-558.

50. Tsai CJ, Leitzmann MF, Willett WC, Giovannucci EL (2004) The effect of long- term intake of cis unsaturated fats on the risk for gallstone disease in men: a prospective cohort study. Ann Intern Med 141: 514-522.

51. Tsai CJ, Leitzmann MF, Willett WC, Giovannucci EL (2005) Long-term intake of trans-fatty acids and risk of gallstone disease in men. Arch Intern Med 165: 1011-1015.

52. Mendez-Sanchez N, Gonzalez V, Aguayo P, Sánchez JM, Tanimoto MA Elizondo J, Uribe M. Fish oil ( $n-3)$ polyunsaturated fatty acids beneficially affect billiary cholesterol nucleation time in obese women losing weight. J Nutr 2001.

53. Tsai CJ, Leitzmann MF, Willett WC, Giovannucci EL (2004) Dietary protein and the risk of cholecystectomy in a cohort of US women: the Nurses' Health Study. Am J Epidemiol 160: 11-18.

54. Ruhl CE, Everhart JE (2000) Association of coffee consumption with gallbladder disease. Am J Epidemiol 152: 1034-1038

55. Leitzmann MF, Stampfer MJ, Willett WC, Spiegelman D, Colditz GA, et al. (2002) Coffee intake is associated with lower risk of symptomatic gallstone disease in women. Gastroenterology 123: 1823-1830.

56. Lammert F, Carey MC, Paigen B (2001) Chromosomal organization of candidate genes involved in cholesterol gallstone formation: a murine gallstone map. Gastroenterology 120: 221-238.

57. Buch S, Schafmayer C, Völzke H, Becker C, Franke A, et al. (2007) A genomewide association scan identifies the hepatic cholesterol transporter ABCG8 as a susceptibility factor for human gallstone disease. Nat Genet 39: 995-999.

58. Grunhage F, Acalovschi M, Tirziu S, Walier M, Wienker TF, et al. (2007) Increased gallstone risk in humans conferred by common variant of hepatic ATP-binding cassette transporter for cholesterol. Hepatology 46: 793-8: 1. 